\title{
Knowledge, Attitudes, Practices and Barriers Towards HPV Vaccination among Nurses in Turkey: a Longitudinal Study
}

\author{
Emre Yanikkerem ${ }^{1 *}$, Gokcen Koker ${ }^{2}$
}

\begin{abstract}
Background: Human papilloma virus (HPV) occurs in women of all age groups, and causes cervical, anal, vaginal, vulvar, penile and oropharyngeal cancers. The aim of the study was to discover what nurses know about HPV infection, testing and vaccination and to determine vaccine practice of their daughters and perceived barriers. Materials and Methods: This cross-sectional and prospective study was carried out nurses who have worked in a hospital between January and June 2014. Pre-test and post-test were used to evaluate the nurses' knowledge about HPV infection, testing and vaccination. This study was performed with nurses who had girls between 9 and 26 years of age for evaluating the behavior of vaccination after three months of education. Results: The mean of pre-test and post-test scores about HPV infection, which included 22 items, were 8.2 \pm 5.6 and 19.2 \pm 1.5 , respectively. Before education the HPV testing knowledge score was remarkably poor $(1.9 \pm 1.7$ over 5), after education it increased to $4.8 \pm 0.5$. The mean $H P V$ vaccine knowledge score were $3.7 \pm 2.7$ (pre-test) $7.3 \pm 0.8$ (post-test) on a $0-8$ scale. The difference between mean total pre-test $(13.9 \pm 9.1)$ and post-test $(31.3 \pm 1.9)$ scores was statistically significant $(\mathbf{p}<\mathbf{0 . 0 0 1})$. After three months of education, only two of the nurses' daughters were vaccinated. The main reason was noted by nurses were not willing to be vaccinated was cost, doubts about safety and efficacy related to the vaccine. About one-third of nurses declared that they would receive the vaccine for their daughter later. Conclusions: Nurses have a crucial role in the prevention, treatment, increasing public awareness and care for population. The education of the nurses about HPV infection, test and vaccination will play an important part decreasing cancer mortality and morbidity.
\end{abstract}

Keywords: Human papilloma virus - HPV - Turkish nurses - knowledge - attitude - education

Asian Pac J Cancer Prev, 15 (18), 7693-7702

\section{Introduction}

In the middle age women, cervical cancer (CC) is the third most common (Ferlay et al., 2010; Wamai et al., 2013), the fourth leading cause of cancer mortality among women cancer in worldwide (Wamai et al., 2013) and with about 500.000 new cases and 250.000 deaths each year (Ferlay et al., 2010; Pinar et al., 2010; Ortashi et al., 2012; Ozyer et al., 2013). In Turkey, CC is the ninth most common cancer among women, the incidence was estimated to be 4.3/100,000 in 2007 (Naki et al., 2010; Ozyer et al., 2013) and estimated mortality rate for $\mathrm{CC}$ was found to be 14.9/100,000 which was ranks 13th among cancer-related deaths. Turkish National Cancer program have administrated cervical screening program which have included a population-based and covers about $70 \%$ of population (Naki et al., 2010; Uzunlar et al., 2013).

Human papilloma virus (HPV) is DNA viruses that infect epithelial (skin or mucosal) cells and is the one of the most common sexually transmitted infection (WHO, 2007; Ozyer et al., 2013). HPV includes more than 100 known genotypes and more than 40 of these viruses can be easily spread through direct skin-to-skin contact during vaginal, anal, and oral sex (National Cancer Institute, 2013). The infection occurs in women of all age groups and it is estimated that over $50 \%$ of sexually active women are exposed to at least one HPV type (Pinar et al., 2010; Makwe and Anorlu, 2011; Ortashi et al., 2012). In the world around 440 million is estimated to cause about half a million new cancers every year, most of them affecting women in developing countries (WHO, 2007; Ozyer et al., 2013). The incidence of HPV infection in Turkey though hospital based studies report ranging from 2.1\%-16.5\% among low-risk Turkish women (Ozyer et al., 2013).

Most HPV infections are asymptomatic, transient, $\% 70-90$ of infection clear within one or two year not causing cancer (Hilton et al., 2011) and persistent infection occurred $10 \%$ of the cases. HPV types have been classified into lower and higher risk groups. The lower risk group (mainly 6 and 11) can cause genital warts (condyloma acuminatum) which grow on the cervix, vagina, vulva, or anus in women and the penis, scrotum, or anus in men. It also causes recurrent respiratory papillomatosis, an uncommon, but serious, condition of the larynx (WHO,

${ }^{1}$ Department of Obstetrics and Gynaecology Nursing, School of Health, Celal Bayar University, Manisa, ${ }^{2}$ Katip Celebi University, Ataturk Training and Research Hospital, Izmir, Turkey*For correspondence: emrenurse@hotmail.com 
2007). The higher risk group (mainly 16 and 18 , also other type $31,33,35,39,45,51,52,56,58,59,66)$ which plays the most important role in the etiology of $\mathrm{CC}$ responsible for about $70 \%$ of all CC (WHO, 2007; National Cancer Institute, 2013) and causes anal, vaginal, vulvar, penile and oropharynx cancers (WHO, 2007; Ozan et al., 2011; Makwe and Anorlu, 2011; Guvenc et al., 2012; National Cancer Institute, 2013).

World Health Organization (WHO) recognizes CC as the first type of carcinoma completely due to an infection and $99 \%$ of CC cases are linked to a HPV infection. Factors contributing to development of CC after HPV infection include immune suppression, multi-parity, early age at first delivery, cigarette smoking, long-term use of hormonal contraceptives, and co-infection with Chlamydia trachomatis or Herpes simplex virus (WHO, 2007). Many studies stated that risk of HPV related mortality and morbidity was seen in women who had socio-economical disadvantaged (Wang and Do, 2012).

Early diagnosis and treatment are an important in reducing the mortality of the $\mathrm{CC}$ and increasing the chance of treatment to $\% 100$, also decreasing the deaths $50 \%$ (Beydag, 2011). Etiologic link between carcinogenic $\mathrm{HPV}$ and $\mathrm{CC}$, testing for molecular HPV testing is now being considered as an alternative for cytology-based CC screening. The sensitivity and specificity of the test for $\geq$ CIN2 was determined between $90 \%$ and $98 \%$ (Kwan et al., 2012). Nowadays, it is suggested that making HPVbased screening is likely to be effective. The combination of HPV and cytology had $100 \%$ sensitivity and a referral rate of 7.9\% (National Cancer Institute, 2013).

The U.S. Preventive Services Task Force (USPSTF) recommends screening for $\mathrm{CC}$ in women age 21 to 65 years with Pap smear every 3 years or, for women age 30 to 65 years, screening with a combination of cytology and HPV testing every 5 years. The USPSTF found new evidence about HPV testing combined with cytology as an acceptable screening strategy for women age 30 to 65 years who prefer to lengthen their screening interval beyond 3 years. The American Cancer Society, American Society for Colposcopy and Cervical Pathology, American Society for Clinical Pathology, had also recommended that women age 21 to 29 years be screened with cytology alone every 3 years. Women age 30 to 65 years should be screened with cytology and HPV testing every 5 years or cytology alone every 3 years (https://www.acog.org/ About_ACOG/Announcements/New_Cervical_Cancer_ Screening_Recommendations).

The HPV vaccine was introduced as a primary prevention strategy to reduce the incidence of CC (Boyce and Holmes, 2012; Wamai et al., 2013) and two types of HPV vaccine (bivalent for HPV 16 and 18; quadrivalent for HPV 6, 11, 16 and 18) were approved for use in CC prevention program for reducing the risk of pre-invasive and invasive neoplasia of the cervix (WHO, 2007; Pinar et al., 2010; Makwe and Anorlu, 2011; Uzunlar et al., 2013). It is estimated that the HPV immunization program will reduce deaths from $\mathrm{CC}$ by two-thirds if uptake reaches $80 \%$. Many countries such as the UK, Australia, Canada, France, Greece, New Zealand, Norway and Sweden offer the HPV vaccine as part of their national immunization program (Boyce and Holmes, 2012). The vaccine seems to be safe, well tolerated and effective if the vaccine has to be delivered before exposure to the virus, and preferably, at the preadolescence stage, as the antibody responses are higher (Ozyer et al., 2013; Uzunlar et al., 2013). The Center for Disease Control and Prevention recommends HPV vaccination among those the age of between 9 and 26 (Holder et al., 2013). There is no need to screen for HPV before offering vaccine to women. The duration of protection has not known yet, but there is evidence of protection for at least five years after vaccination. Studies have been continuing to evaluate the long-term protection. The cost of HPV vaccines will be a major determinant of the cost-effectiveness of vaccination (WHO, 2007).

In Turkey, cervical screening primarily based on Pap smear and HPV testing currently have a limited use because of its high cost. HPV testing is recommended to women with atypical squamous cells of undetermined significance (ASCUS). Pap smear is taken by doctors and trained nurses. The vaccines have been in use since 2007; however, the cost of vaccines has not covered by health insurance. Especially for in developing countries, health care providers play an important role in immunization programs for providing health education to public and to play a significant role in the success of effective HPV vaccine program (Naki et al., 2010; Makwe and Anorlu, 2011; Mc Sherry et al., 2012; Uzunlar et al., 2013).

Health care providers' especially nurses in developing countries play a crucial role in taking smear, giving an information and advising for their patients on HPV infection, HPV related condition, HPV testing and vaccination. Various international studies have demonstrated that health care professionals had a basic knowledge about CC, HPV and related disease, HPV tests and HPV vaccine; but lack detailed knowledge (Makwe and Anorlu, 2011; Phianmongkhol et al., 2011; Kwan et al., 2012; Ortashi et al., 2012) and also previous studies indicated that women have desired information about HPV and CC, parents and women considering having their daughters vaccinated for HPV vaccine recommendation from health professionals to be important predictor of vaccine receipt (Pinar et al., 2010; Yanikkerem et al., 2010; Wong and Do, 2012).

In Turkey most of studies evaluated the knowledge and attitudes of women (Pinar et al., 2010; Ozan et al., 2011; Ozyer et al., 2013), medical students (Onsuz et al., 2011), nursing students (Ozsaran et al., 2011; Guvenc et al., 2012; Uzunlar et al., 2013), university students (Yanikkerem et al., 2010), nurses (Pinar et al., 2007), physicians and non-physician health care professionals (Naki et al., 2010), and pediatricians (Yildirim et al., 2009) about HPV and vaccinations. Only one study had given education to university students about HPV and HPV vaccine (Yanikkerem et al., 2010). However, no published research was found a longitudinal design about vaccination.

It has been noted that although CC is a preventable disease, in many developing countries screening program is lack and nurses generally play a major role in health education and prevention (Phianmongkhol et al., 2011). The knowledge and perceptions of health professionals are 
an important factors in influencing vaccine acceptability, however little is known about nurses knowledge and attitude on the HPV vaccination program. In Turkey there were no studies on the nurse's role play in implementing a HPV vaccination.

The aim of the study was (1) to evaluate the basic knowledge of nurses about HPV infection, HPV testing and HPV vaccine, (2) to determine effect of education program for nurses' level of knowledge about HPV infection, HPV testing and HPV vaccine and (3) to assess the effect of education session for nurses' attitudes towards vaccinations and (4) to explore nurses' practice of HPV vaccine to their daughters and perceived barriers of HPV vaccinations.

\section{Materials and Methods}

\section{Sample of the study}

The cross-sectional and prospective study was carried out nurses who have worked in Katip Celebi University, Ataturk Training and Research Hospital between January and June 2014. The hospital that is the central training hospital in Izmir, which is the third biggest cities of Turkey, provides services to adult in all departments of health conditions.

At the time of the study, there were 832 nurses that have employed in the hospital. This study was performed with 143 nurses who had girls between 9 and 26 years of age for evaluating the behavior of vaccination after education section. Overall, 143 nurses invited in the study, however 13 of them did not participate the research and education session, 10 nurses did not work in the hospital between the dates, 15 nurses participated the education session but did not want to complete the questionnaire. Finally, this study sample consisted of 105 nurses.

\section{Questionnaire}

The self-administered questionnaire, which was consisted of five parts, was designed by the researchers on the basis of published research, expert opinion and guidance (WHO, 2007; Yanikkerem et al., 2010; Makwe and Anorlu, 2011; Phianmongkhol et al., 2011; Kwan et al., 2012; Marlow et al., 2013; Wamai et al., 2013; National Cancer Institute, 2013).

The first section included 14 questions to elicit information about nurses' demographic, professional and fertility characteristics, i.e. age, level of education, marital status, number of previous pregnancies and the number of children. The sources of information about HPV also asked in the part.

The second section comprised pretest and the third part involved posttest questions about HPV. The content validity was assessed by obstetricians and gynecology experts and revised for suggestion. The pretest and posttest questionnaire which consisted of 35 items about HPV in order to determine the knowledge related to HPV infection (22 items), HPV testing ( 5 items) and HPV vaccine ( 8 items). Nurses were given information about the aim of the study. We asked nurses before the education session, "Before today, have you ever heard about HPV?" And we explain the nurses "Please full the questionnaire and if you did not heard of HPV, please check in "I don't know". The response option for all items in pretest was true/false/ I don't know. After in pretest section education was given to nurses about HPV by the second author. However, in posttest the response option was true and false. The questions and correct answers as supported by evidence were shown in Table 1 and 2.

Education session was developed from the literature and guidelines by the researchers. The session was included information about HPV infection (transmission, related condition, risk factors), HPV testing and HPV vaccine. Nurses were gathered in the hospital seminar room by hospital management organization during working hours. The average number of nurses in the seminar hall was 21 were educated at different times. After gathering in the seminar room, nurses first completed the first part of questionnaire which included sociodemographic questions and the pre-test questionnaire. After the education session, the post-test and the fourth part of questionnaire were administered.

The fourth part of questionnaire included 8 items to assess about nurses' attitudes towards HPV vaccination and the part was completed after the education session. A three-point Likert scale was used to determine attitude towards the HPV vaccine. The items are close-ended with possible responses including "I agree", "I undecided", and "I disagree".

After three months of education, the last part was asked by using telephone interview. The part was aimed to assess nurses' behaviors towards vaccinations of their own daughters and included barriers of HPV vaccination and reason for uptake HPV vaccine. The interviews lasted an average one hour (pretest 15 minutes, education session 30 minutes, post-test 15 minutes, attitude questionnaire 5 minutes, telephone interview 5 minutes for every nurse).

\section{Ethics of the study}

Before pretest the objectives of the study were explained to the nurses and informed consent was taken from all nurses. Ethics approval was obtained from Katip Celebi University.

\section{Analysis}

Data were recorded and analyzed by using SPSS version 17.0. Basic descriptive findings were analyzed using frequency distributions. The 22 questions' for HPV infection, 5 questions for HPV testing and 8 questions for HPV vaccination correct answers were summed to create knowledge score. A total HPV knowledge score was computed by determining the total number of correct responses range between 0 and 35 . Two knowledge scores were calculated for each part: before the education intervention (pretest), after the education intervention (post-test). In the pretest questionnaire, a score of 1 was given for each correct response and 0 for each incorrect or don't know response. One (1) mark was given for every correct response and zero (0) for an incorrect response in the post test section.

Both the mean values for each question and total knowledge score were compared (pre-test and post-test) by using paired t-test, in order to evaluate whether baseline 
Emre Yanikkerem and Gokcen Koker

knowledge improved significantly after the education intervention was administered. A $p$ value of less than 0.05 was considered to be statistically significant. Association between nurses' demographics/ professional characteristics and pretest questionnaire (total knowledge score about HPV infection, HPV test and HPV vaccinations) were analyzed by using t-test, Anova, Mann Whitney U and Kruscal Wallis test.

\section{Results}

\section{Characteristics of study population}

Out of 145 nurses 105 participated in the study and a response rate was found to be $87.5 \%$. In the study, $51.4 \%(n=54)$ of nurses were less than 40 years old and the mean age was $39.8 \pm 5.4$ years of nurses ranged in age from 29 to 54 years. It was determined that $52.4 \%$ of nurses had over 20 years of experience, $86.7 \%(n=91)$ of them married, $42.6 \%(n=45)$ of them had university education (graduate and undergraduate). Overall, $58.1 \%(\mathrm{n}=61)$ had $\geq 2$ parity, $35.2 \%$ $(n=37)$ had girl and boy, $64.8 \%(n=68)$ had only girl child. Forty-two (40.0\%) nurses reported ever having an annual gynecological examination, 65.7\% ( $n=69)$ of the nurses visited outpatient clinic for Pap smear once a year and $13.3 \%(n=14)$ of the participants had CC history their relatives and friends.

The present study, $90.5 \%(n=95)$ and $14.5 \%(n=90)$ of the respondents stated that they had heard about HPV and its vaccines previously, respectively. Only fourteen nurses $(13.3 \%)$ had taken education or course about HPV and vaccination. Among those who had heard of the HPV infection, their main source of information was written material (newspaper, magazines, journals) (31.4\%), television $(17.1 \%)$, internet $(15.2 \%)$, friends (14.3\%), professional training course $(12.4 \%)$ and other $(9.5 \%)$. Nurses who had heard of HPV vaccine had learned about it from written material $(34.3 \%)$, friends $(16.2 \%)$, internet $(12.4 \%)$, television $(11.4 \%)$, professional training course $(11.4 \%)$ and other $(14.3 \%)$ (Data not shown).

\section{Nurses' knowledge about HPV infection} before and after education

Data regarding pre- and post-test knowledge about HPV infection were presented in Table 1 . In pretest findings, only $36.2 \%$ and $45.7 \%$ of nurses knew HPV infection occurs in both women and men and HPV infection is generally asymptomatic, respectively. Only $12.4 \%$ of nurses recognized HPV is an infection as resolved on their own 1 to 2 years. HPV infection is transmitted by

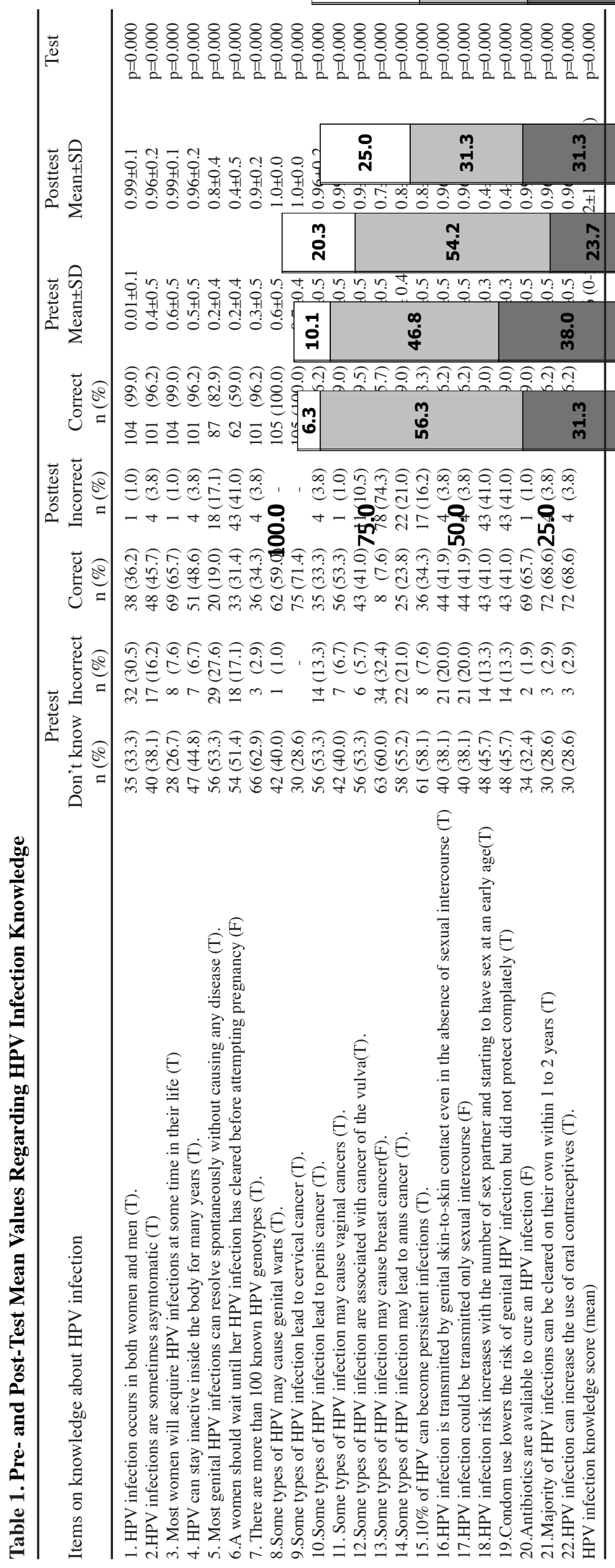


Knowledge, Attitudes, Practices and Barriers Towards HPV Vaccination among Nurses in Turkey: a Longitudinal Study

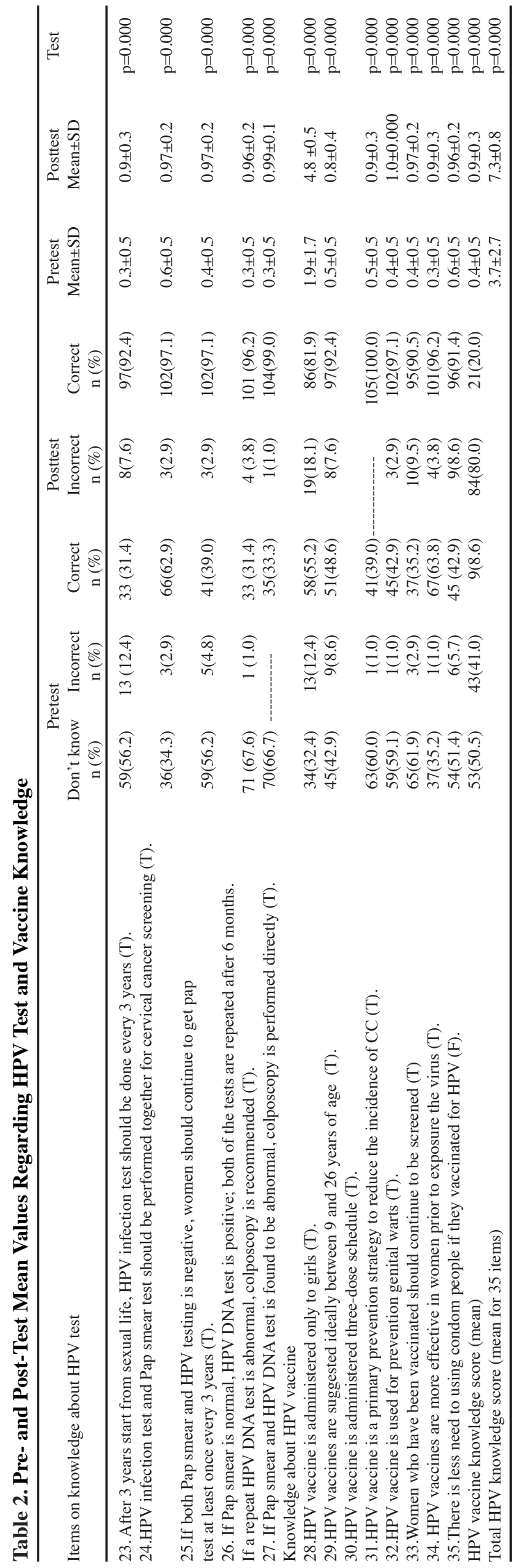

genital skin to skin contact was known only $41.9 \%$ of the nurses. According to pretest results, only a third of the nurses $(34.3 \%)$ knew high-risk HPV type could lead to persistent infection. Only $13.3 \%$ of nurses knew correctly the statement "HPV could transmit through only sexual intercourse". Of the nurses $65.7 \%$ answered correctly "having multiple sex partners and starting to have sex at an early age increases the risk of HPV infection".

Seven out of ten nurses (71.4\%) were aware of the relationship between $\mathrm{CC}$ and HPV infection, more than half of the nurses (59.0\% and 53.3\%) were aware of HPV might cause genital warts and vaginal cancer, respectively. Overall, $41.0 \%, 23.8 \%$ and $33.3 \%$ of them knew "some types of HPV infection are associated with vulvar, anal and penile cancer", respectively. Knowledge of the no association between HPV and breast cancer increased over tenfold from $7.6 \%$ to $74.3 \%$. About one out of four nurses $(26.7 \%)$ stated that HPV cannot be cured with antibiotics.

Before education, nurses completed a 22 item HPV infection questionnaire and the mean number of items correctly was $8.2 \pm 5$.6. After education the mean value increased as $19.2 \pm 1.5$ and nurses were able to provide the correct answers to most of the questions about HPV infection. The difference between mean pre- and post- test scores was statistically significant $(\mathrm{p}<0.001)$ (Table 1).

Nurses' knowledge about HPV testing and vaccination before and after education

Nurses knowledge about HPV testing and vaccination increased significantly for all items and comparison of pre-posttest questionnaire was performed in Table 2. Only $31.4 \%$ responded to questions correctly on the frequency of HPV testing and more than onethird of the nurses $(37.2 \%)$ answered incorrectly CC could be prevented with both HPV test and Pap smear test together. The majority of respondent (66.7\%) did not know "If Pap smear and HPV DNA test was found abnormal, colposcopy was performed directly". After education, the ratio was increased $99.0 \%$ among the nurses. In the pretest question, "If both Pap smear and HPV test is negative, women should continue to get Pap test at least once every 3 years" was answered correctly by $39.0 \%$ of nurses. After education session, $97.1 \%$ nurses answered this question. There were significant differences in nurses' pretest and posttest result $(\mathrm{p}<0.001)$.

In the pretest section, almost half of nurses (48.6\%) knew correctly 9-26 years of age is the appropriate age of vaccination and only $39.0 \%$ knew the dosing scheme of the HPV vaccine. Before education, $42.9 \%$ of nurses mentioned that HPV vaccine is a primary prevention strategy to reduce the incidence of CC. About a third of nurses $(35.2 \%)$ correctly answered HPV vaccine was used for genital warts.

In pretest, about one-third of nurses $(35.2 \%)$ did not know women who had been vaccinated should continue to be screened and correct response went from $63.8 \%$ to $96.2 \%$ after education. "HPV vaccines 
Emre Yanikkerem and Gokcen Koker

are more effective in women prior to exposure the virus" and "There is less need to using condom if they vaccinated for HPV" questions had correct response rate on the pretest questionnaire $(42.9 \%$ and $41.0 \%$ respectively). After education, correct answers reached $91.4 \%$ and $80.0 \%$ respectively. There was significant increase in knowledge scores between pre-test and post-test questions $(\mathrm{p}<0.001)$.

The HPV testing knowledge score in pretest was remarkably poor (1.9 over 5$)$ and the mean HPV vaccine knowledge score was found $3.7 \pm 2.7$ on a $0-8$ scale.

\section{Relationship between nurses' characteristics and pre-test} scores

No statistically significant relationship has been determinate between the nurses' knowledge about HPV (HPV infection, HPV testing, HPV vaccination and total score of HPV) and the demographic characteristics (nurses' age, duration of working time, marital status, parity, income level, number of children, gender of children). The study found that knowledge of HPV infection score was significantly higher in higher educated nurses. Nurses with undergraduate education and over had higher level of knowledge about the HPV infection.
A statistically significant relationship was found between HPV total knowledge score and having been previously informed about HPV. The mean HPV total knowledge score for nurses who had training course was $17.4 \pm 8.8$ and nurses who had training course about HPV had higher mean knowledge scores about HPV vaccination than nurses who had not. Details of the data were given in Table 3.

\section{Nurses attitudes towards HPV vaccination}

Nurses' attitudes towards HPV vaccination were shown in Table 4. After education, the most common reasons against vaccination given by nurses concerned about cost of vaccine (79.0\%), vaccine safety (41.9\%) and vaccine efficacy (44.8\%). Overall, $71.4 \%$ of nurses disagreed that giving the vaccine would increase risky behavior and early onset of sexual activity.

In the study, $26.7 \%$ of nurses thought it were not necessary to vaccinate boys, whereas only $37.1 \%$ of nurses believed it was necessary to vaccinate boys. Most of the nurses $(91.4 \%)$ felt that adolescent sex education should be given before recommending the vaccine. Majority of the participants $(91.4 \%)$ stated that adolescent sex education

\section{Table 3. Relationship between Nurses' Characteristics and Pre-Test Scores}

\begin{tabular}{|c|c|c|c|c|c|c|c|c|}
\hline \multirow[t]{2}{*}{ Characteristics of the nurses } & \multicolumn{2}{|c|}{$\begin{array}{l}\text { Knowledge about } \\
\text { HPV infection }\end{array}$} & \multicolumn{2}{|c|}{$\begin{array}{c}\text { Knowledge about } \\
\text { HPV test }\end{array}$} & \multicolumn{2}{|c|}{$\begin{array}{l}\text { Knowledge about } \\
\text { HPV vaccine }\end{array}$} & \multicolumn{2}{|c|}{$\begin{array}{l}\text { Knowledge about } \\
\text { total HPV items }\end{array}$} \\
\hline & Mean \pm SD & Test & Mean \pm SD & Test & Mean \pm SD & Test & Mean \pm SD & Test \\
\hline Age of nurses & & $\mathrm{t}=-0.728$ & & $t=-0.669$ & & $\mathrm{t}=-0.885$ & & $\mathrm{t}=-0.828$ \\
\hline 40 age $\leq$ & $7.8 \pm 5.8$ & $\mathrm{df}=103$ & $1.9 \pm 1.7$ & $\mathrm{df}=103$ & $3.5 \pm 2.8$ & $\mathrm{df}=103$ & $13.1 \pm 9.0$ & $\mathrm{df}=103$ \\
\hline 40age $\geq$ & $8.6 \pm 5.4$ & $\mathrm{p}=0.468$ & $2.1 \pm 1.8$ & $\mathrm{p}=0.505$ & $3.9 \pm 2.8$ & $\mathrm{p}=0.409$ & $14.6 \pm 9.2$ & $\mathrm{p}=0.409$ \\
\hline Education of nurses & & $\mathrm{t}=-2.240$ & & $t=-1.702$ & & $\mathrm{t}=-0.903$ & & $t=-1.947$ \\
\hline High school degree & $7.1 \pm 5.5$ & $\mathrm{df}=103$ & $1.7 \pm 1.7$ & $\mathrm{df}=103$ & $3.4 \pm 2.6$ & $\mathrm{df}=103$ & $12.4 \pm 9.0$ & $\mathrm{df}=103$ \\
\hline Graduate or postgraduate degree & $9.6 \pm 5.3$ & $\mathrm{p}=0.027$ & $2.3 \pm 1.7$ & $\mathrm{p}=0.092$ & $3.9 \pm 2.6$ & $\mathrm{p}=0.369$ & $15.8 \pm 9.0$ & $\mathrm{p}=0.054$ \\
\hline Duration of working time & & $\mathrm{t}=-0.842$ & & $\mathrm{t}=-1.131$ & & $\mathrm{t}=-1.887$ & & $\mathrm{t}=-1.273$ \\
\hline 20 years $\leq$ & $7.7 \pm 5.6$ & $\mathrm{df}=103$ & $1.8 \pm 1.7$ & $\mathrm{df}=103$ & $3.9 \pm 2.3$ & $\mathrm{df}=103$ & $12.7 \pm 8.8$ & $\mathrm{df}=103$ \\
\hline 20 years $\geq$ & $8.6 \pm 5.5$ & $\mathrm{p}=0.402$ & $2.2 \pm 1.8$ & $\mathrm{p}=0.260$ & $4.1 \pm 2.9$ & $\mathrm{p}=0.062$ & $14.9 \pm 9.4$ & $\mathrm{p}=0.206$ \\
\hline Marital status & & $\mathrm{MWU}=578.0$ & & MWU $=598.0$ & & $\mathrm{MWU}=623.5$ & & MWU $=585.0$ \\
\hline Married & $8.3 \pm 5.6$ & $\mathrm{p}=0.577$ & $2.0 \pm 1.8$ & $\mathrm{p}=0.708$ & $3.7 \pm 2.7$ & $\mathrm{p}=0.898$ & $14.0 \pm 9.3$ & $\mathrm{p}=0.624$ \\
\hline Unmarried & $7.6 \pm 5.2$ & & $1.7 \pm 1.5$ & & $3.6 \pm 2.5$ & & $12.3 \pm 8.3$ & \\
\hline Parity & & $\mathrm{t}=-0.917$ & & $\mathrm{t}=-1.043$ & & $t=-1.669$ & & $\mathrm{t}=-1.240$ \\
\hline 1 & $7.6 \pm 5.8$ & $\mathrm{df}=103$ & $1.8 \pm 1.7$ & $\mathrm{df}=103$ & $3.2 \pm 2.6$ & $\mathrm{df}=103$ & $12.6 \pm 9.4$ & $\mathrm{df}=103$ \\
\hline $2 \geq$ & $8.6 \pm 5.3$ & $\mathrm{p}=0.362$ & $2.1 \pm 1.8$ & $\mathrm{p}=0.299$ & $4.0 \pm 2.6$ & $\mathrm{p}=0.098$ & $14.8 \pm 8.9$ & $\mathrm{p}=0.218$ \\
\hline Gender of children & & $\mathrm{t}=-0.095$ & & $\mathrm{t}=-1.024$ & & $\mathrm{t}=-0.048$ & & $t=-0.266$ \\
\hline Girl & $8.2 \pm 5.6$ & $\mathrm{df}=103$ & $1.8 \pm 1.6$ & $\mathrm{df}=103$ & $3.7 \pm 2.7$ & $\mathrm{df}=103$ & $13.7 \pm 9.3$ & $\mathrm{df}=103$ \\
\hline Girl and boy & $8.3 \pm 5.5$ & $\mathrm{p}=0.924$ & $2.2 \pm 1.9$ & $\mathrm{p}=0.308$ & $3.7 \pm 2.6$ & $\mathrm{p}=0.962$ & $14.1 \pm 8.9$ & $\mathrm{p}=0.791$ \\
\hline Have you ever heard of HPV? & & & & & & & & \\
\hline Yes & $8.7 \pm 5.3$ & MWU=209.5 & $2.0 \pm 1.7$ & MWU $=358.5$ & $3.9 \pm 2.6$ & MWU $=267.0$ & $14.6 \pm 8.8$ & MWU $=235.0$ \\
\hline No & $3.2 \pm 5.8$ & $\mathrm{P}=0.004$ & $1.3 \pm 1.5$ & $\mathrm{P}=0.195$ & $1.9 \pm 2.5$ & $\mathrm{P}=0.022$ & $6.4 \pm 9.4$ & $\mathrm{p}=0.009$ \\
\hline Sources of knowledge about HPV & & & & & & & & \\
\hline Written material & $10.5 \pm 4.4$ & & $2.1 \pm 1.6$ & & $4.2 \pm 2.3$ & & $16.9 \pm 7.3$ & \\
\hline Television & $9.0 \pm 4.8$ & & $2.4 \pm 1.9$ & $\mathrm{KW}=6.658$ & $4.5 \pm 2.3$ & $K W=8.672$ & $15.9 \pm 8.3$ & $K W=11.996$ \\
\hline Professional course & $9.9 \pm 5.3$ & $K W=12.945$ & $2.8 \pm 1.9$ & $\mathrm{df}=4$ & $4.7 \pm 2.6$ & $\mathrm{df}=4$ & $17.4 \pm 8.8$ & $\mathrm{df}=4$ \\
\hline Friends & $5.1 \pm 6.3$ & $\mathrm{df}=4$ & $1.5 \pm 1.7$ & $\mathrm{p}=0.155$ & $2.9 \pm 3.2$ & $\mathrm{p}=0.070$ & $9.5 \pm 10.6$ & $\mathrm{p}=0.017$ \\
\hline Internet & $7.0 \pm 4.9$ & $\mathrm{p}=0.012$ & $1.4 \pm 1.5$ & & $2.6 \pm 2.4$ & & $11.1 \pm 7.9$ & \\
\hline Other & $8.7 \pm 5.3$ & & $2.0 \pm 1.7$ & & $3.9 \pm 2.6$ & & $14.6 \pm 8.9$ & \\
\hline
\end{tabular}

Table 4. Nurses Attitudes' Towards HPV Vaccination

\begin{tabular}{|c|c|c|c|}
\hline Nurses attitudes' towards HPV vaccination & I agree & I undecided & I disagree \\
\hline I am concerned about the effectiveness of the HPV vaccine & $47(44.8)$ & $51(48.6)$ & $7(6.7)$ \\
\hline I am concerned about the reliability of the HPV vaccine & $44(41.9)$ & $46(43.8)$ & $15(14.3)$ \\
\hline HPV vaccine is very expensive, so people could not vaccinated & $83(79.0)$ & $7(6.7)$ & $15(14.3)$ \\
\hline HPV vaccine may encourage unprotected sexual intercourse & $27(25.7)$ & $14(13.3)$ & $64(61.0)$ \\
\hline HPV vaccine may encourage starting to have sex at an early age & $17(16.2)$ & $13(12.4)$ & $75(71.4)$ \\
\hline Boys should be vaccinated although the vaccine is not recommended & $39(37.1)$ & $38(36.2)$ & $28(26.7)$ \\
\hline Adolescent sex education should be given prior to vaccination. & $96(91.4)$ & $2(1.9)$ & $7(6.7)$ \\
\hline Health care providers and teachers should be informed about HPV infection and HPV vaccine. & $102(97.1)$ & ---------- & $3(2.9)$ \\
\hline
\end{tabular}


should be provided before the vaccination.

Vaccination status of nurses' daughters and reasons for not receive vaccination

Only two of the nurses' daughters were vaccinated after 3 months of education and the main reason listed among nurses were not willing to be vaccinated was cost $(n=40,38.8 \%)$, doubts about safety $(n=16,15.5 \%)$ and efficacy $(n=12,11.4 \%)$ related the vaccine. Overall, 37 of nurses $(35.2 \%)$ stated that they would receive the vaccine their daughter later (data not shown).

\section{Discussion}

The aim of the present study was one of the first to evaluate the knowledge regarding HPV infections, testing and vaccine and provides a detailed picture of knowledge, attitude, practice and barriers towards vaccination among Turkish nurses who participated training course about the issue. Nurses' knowledge about HPV was evaluated in the study because nurses are often the first point of contact with patients; play an important role in promoting/ delivering immunizations programs for vaccines and increasing public awareness about the HPV and CC. And also nurses have an important role in the prevention, treatment, education and care for patients and they are working in all parts of population for helping women to give positive and true knowledge. It has been noted that although $\mathrm{CC}$ is a preventable disease, in many developing countries screening program is lack and nurses generally play a major role in health education and prevention. The earlier studies also stated that participants were more likely to agree to HPV vaccination when recommended by their health care providers (Yanikkerem et al., 2010; Rosenthal et al., 2011).

In the light of the study findings, before education sessions most of the nurses had inadequate basic knowledge about HPV infections, tests and vaccines and low points of pretest questionnaire. Almost one out of ten nurses $(9.5 \%)$ stated that they had never heard about HPV infection and $14.3 \%$ of them had not heard of the vaccine. Similiarly with other previous studies, in United Arap Emirates nearly all of school nurses (97\%) (Ortashi et al., 2012), in Nigeria $84.8 \%$ of the nurses (Makwe and Anorlu, 2011), $81.0 \%$ of non-physician health care providers and $97.2 \%$ of physician (Naki et al., 2010) and in Ankara, Turkey $55.7 \%$ of the nurses students (Guvenc et al., 2012) had heard of HPV infection. According to Marlow et al (2013) study findings, $61.1 \%$ of participants had heard of HPV. In South Africa $73.3 \%$ of the nurses were aware of HPV; however nurses had poor knowledge regarding HPV infection and the vaccine (Hoque et al., 2014). In Cameroon, nurses had moderately low levels of knowledge about HPV infection, however moderately high level of knowledge about HPV vaccine (Wamai et al., 2013).Contrary to our results, one study stated that the level of knowledge for midwives and nurses about HPV vaccine and CC was found to be sufficient (Beydag, 2011).

Written materials, television and internet were the most important source of knowledge among nurses who had heard about the HPV while a small proportion of nurses had heard about it through the training course. Similarly, most of studies stated that source of information about HPV and HPV vaccine was written material, media and television (Beydag, 2011; Phianmongkhol et al., 2011). One study in nursing students in Turkey stated that the major source of information about HPV vaccine was the media, internet and their friends (Uzunlar et al., 2013).

In the study, almost two-third of the nurses was unaware of that both men and women have an equal risk of infection. In Cameroon the ratio was found $40.8 \%$ (Wamai et al., 2013). Most of the nurses did not know that HPV infection was generally asymptomatic. The finding is similar to other studies (Phianmongkhol et al., 2011). Although HPV could be transmitted by skin-to- skin contact, in the study, less than half of the nurses identified genital skin-to-skin contact as way of transmission of HPV and nurses mistakenly believed that HPV infection can be contaminated only sexual intercourse. Similarly almost half of the nursing students in Turkey identified sexual intercourse as a way of transmission of HPV (Uzunlar et al., 2013). In Nigeria 7.3\% of nurses knew HPV infection was contacted by genital skin to skin contact (Makwe and Anorlu, 2011). Consistent with our findings, one study in Thailand more than $70 \%$ of the nurses were correctly identified risk factors for $\mathrm{CC}$ as smoking, having multiple sexual partners and starting to sex an early age (Phianmongkhol et al., 2011).

It was determined that the misbelieved about HPV could be treated using antibiotics and did not recognize HPV infection was incurable diseases $(55.2 \%$ of them said did not know, $18.1 \%$ of them marked incorrect answer). Of the nurses $12.4 \%$ answered correctly that majority HPV infection could clear on their own within 1-2 years. However, the knowledge about the information was quite low. Similarly in our findings, in Cameron $26.3 \%$ of the nurses (Wamai et al., 2013) and in Christchurch 52\% of the participants were unaware of most HPV infections can be disappeared without medical treatment on their own (Henninger, 2009).

Using condom can be decreased risk of HPV dramatically, but condom is not as protective against HPV (Marlow et al., 2013). Condoms are an effective tool for preventing STI if used consistently and correctly. Studies have been noted that although use of condoms decreases the risk of HPV, the incidence of HPV among condom users still remains high (Phianmongkhol et al., 2011). In the study before education $68.6 \%$ of the nurses decelerated that condom use lowers the risk of genital HPV infection but did not protect completely. In one study, 59.2\% of the nurses considered condom use as an important means of protection against HPV infection (Wamai et al., 2013).

Before education most of the nurses $(71.4 \%)$, after education all of nurses knew correctly HPV infection was related to CC. Similarly, when the literature was viewed, it was seen that of nurses $70.1 \%$ in Nigerian (Makve and Anorlu, 2011), 78.5\% in Greece (Dinas et al., 2009), 710\% in New Zealand (Henninger, 2009), 80.0\% in United Arap Emirates (Ortashi et al., 2012) and 81.8\% in Thailand (Phianmongkhol et al., 2011) knew about the relationship between CC and HPV infection. In Turkey 92.9\% of the pediatricians (Yildirim et al., 2009), 76.9\% 
of nursing students (Uzunlar et al., 2013), in Christchurch $73.0 \%$ of health care providers (Henninger et al., 2009) and in Hong Kong $44.4 \%$ of primary care physicians (Wong et al., 2013) knew that HPV infection was the most important risk factor for CC. Other study stated that $90.8 \%$ of the participants knew that CC is directly linked to HPV infection (Wamai et al., 2013).

In the study, about four out of five nurses did not know about the link between HPV and anal cancer, almost two-thirds of the participants were unaware of the virus may cause penis cancer. HPV infection is acknowledged incorrectly as a causal factor for breast cancer and the information is not well known among nurses in the present study. Knowledge about HPV related diseases also increased significantly, after education. Consistent with the findings, one study determined that most of the nurses answered incorrectly the question HPV commonly caused of anal cancer (Phianmongkhol et al., 2011). In the pretest section, the level of knowledge about HPV infection was significantly higher in nursing group who were participated training program about HPV and had higher education level.

Another finding of the study was that nurses' knowledge about HPV testing might be considerably inadequate and most were still unaware of HPV testing, despite nurses had a general knowledge of HPV infection. Nurses in the study have worked in different clinics in the hospital and the situation might cause the lower knowledge of HPV testing. Similar findings have been reported in other researches (Linnehan et al., 1996; McSherry et al., 2012).

Almost 10 years had passed since the US FDA Licensed the HPV vaccine; however the light of the study findings indicated that nurses' HPV vaccine knowledge was found an inadequate. Six out of ten nurses had poor knowledge about HPV vaccine. In the present study, less than half of respondents knew CC could be prevented by HPV vaccine. As reported in some studies, in Nigeria only $13.0 \%$ of the nurses (Makwe and Anorlu, 2011), in Thailand, $47.7 \%$ of nurses (Phianmongkhol et al., 2011), in Ankara and Izmir, Turkey, $54.8 \%$ and $75.7 \%$ nursing students, respectively (Ozsaran et al., 2011; Guvenc et al., 2012), in Turkey $76.9 \%$ of the pediatricians (Yildirim et al., 2009) knew CC could be prevented through vaccine. In one study Ankara, Turkey 78.0\% nursing students had heard of HPV vaccine (Uzunlar et al., 2013).

Wamai et al (2013) stated that $78.9 \%$ of nurses recognized HPV vaccine as an important means of protection against HPV infection. Klug et al (2008) stated that in their systematic review, there were no differences between countries in regard to knowledge of HPV and since HPV vaccination became available, awareness of HPV has increased (Klug et al., 2008). One study was carried out 2409 participants in three countries and found that awareness of HPV and vaccination was higher in the US than in Australia and the UK (Marlow et al., 2013). Education program about the vaccine should focus on the health care providers as well as the women. In the study more than half of nurses were aware of vaccination does not rule out the need for future CC screening. Studies stated that messages about the need for future screening may need to be pointed out with clear information about the vaccine which did not prevent all CC (Marlow et al., 2013).

Less than half of nurses knew that HPV vaccine was most effective if given to people who have never had sex. The reason for low level of knowledge in nurses might be there was no vaccination program and clinical guidelines about HPV in Turkey. In particular, correct identification of three dose schedule for HPV vaccine increased from $39 \%$ to $100 \%$. The study findings suggest that there is need for education program, which includes specifics information about HPV vaccine such as timing, dosing and connection between HPV vaccine and Pap test, for health providers to developing knowledge, behaviors and attitude. After education session most of knowledge items on HPV were answered correctly by the nurses in the posttest questionnaire ( 30 of the 37 items) and it was determined that the nurse's knowledge of HPV was found higher rate.

Studies was pointed out that recommendation of HPV immunization by health care providers has been determined as one of the most influential factors in the individual's willingness to receive vaccine. Research indicated that attitudes and supports of nurses and physicians towards HPV vaccine influenced vaccination uptake and increase vaccination rates (Riedesel et al., 2005; Kwan et al., 2012). It is important that women should be informed about HPV and HPV vaccine for women and their family member's health. Nurses are a key people for increasing women's knowledge.

Many nurses $(98.1 \%)$ in the current study had not vaccinate their children after education intervention cost of vaccine, nurses' concern about vaccine safety and efficacy were determined as major barriers. The main barriers about HPV vaccination in the study was found similar to previous researches (Duval et al., 2009; Naki et al., 2010; Hilton et al., 2011; Wamai et al., 2013; Wong et al., 2013; Ozyer et al., 2013). Oldac and Katz, (2012) study conducted 46 public health departments which served to 32 countries of Ohio Appalachia. The most common barriers reported for nurses were lack of knowledge about HPV vaccines, concerns about vaccine side effects, the newness of HPV vaccines, parents believing their children are not sexually active/too young. The vaccine is being used in more than 100 countries and some of the countries have implemented to HPV vaccination as part of a national routine immunization program. But this has not occurred in Turkey yet.

In Turkey studies have examined about barriers on HPV vaccine; $80.5 \%$ of medical students stated that possibility to suggest the vaccine might increase in case the vaccine would be free. High price of vaccine $(51.6 \%)$ and the belief about the vaccine would increase unprotected sexual intercourse $(45.9 \%$ ) were found the most important drawback points of the students in suggesting vaccine to girls' parents (Onsuz et al., 2011). Other study also underlined the concern of $76.9 \%$ of the pediatricians, not recommending vaccination, was the vaccination cost, while $46.2 \%$ of them had concerns considering the worries of parents about the probability for the vaccination to cause risky sexual behaviors (Yildirim et al., 2009). 
Lack of information also determined the most important barrier to vaccination (Ozyer et al., 2013). The attitude of nurses regarding HPV vaccine will play a critical role in the administration of the vaccine. Other study underlined the most important factors for recommending the vaccine was effectiveness $(56.6 \%)$ and safety side effects $(11.8 \%)$ and cost was less of concern (6.6\%) (Wamai et al., 2013).

HPV infection can affect both women and men. For control of HPV transmission the role of men should be considered. Consistently Hilton et all's (2011) study findings, in the present study higher in one thirds of the nurses $(37.1 \%)$ stated that boys should be vaccinated although recommended routinely. Immunization of males with the quadrivalent vaccine, although permitted, was not recommended routinely. Holder et al (2013) study stated that $84 \%$ of adolescent health care providers offered the quadrivalent vaccine to males despite the lack of a routine recommendation from the CDS (Holder et al., 2013).

It was emphasized in many studies education about HPV and HPV vaccine has played a crucial role in vaccine acceptability in the general population (Freidman and Shepeard, 2007; Gottval et al., 2010; Reiter et al., 2011; Uzunlar et al., 2013; Tonguc et al., 2013). In the present study it was evaluated for vaccinated rate among nurses' daughters and contrary to previous studies found only two of nurses had been vaccinated their daughters after three months of education. In the study, among nurses whose daughters have not received the vaccine yet, only $35.3 \%$ of nurses reported high probability for their daughter would get vaccinated within next year. It was probably willingness to receive their daughters was influenced by the nurses' own attitude about vaccine efficacy and safety. The attitude of the vaccine was the most important in our study findings. This may be considered as one of the reasons why the vaccination rate was very low among the nurses' daughters'. In Izmir, Turkey, among 129 female students only 5 of them had HPV vaccination (Ozsaran et al., 2011). Another study in Turkey determined only $2.1 \%$ of the nursing students were vaccinated and $66.3 \%$ of the the nursing students wanted to willingness to be vaccinated currently (Uzunlar et al., 2013). An achieving success in HPV vaccination programs may be more difficult than other vaccination programs. The cost of the HPV vaccine was reported a major obstacle to uptake HPV vaccine. Recommended three dose course costs were approximately US \$ 390 .

The findings of the study have numerous important implications for practice. The study was the first evaluation of HPV educational intervention and in the date no similar intervention for nurses has been conducted in Izmir, Turkey. The education of the nurses about HPV infection, test and vaccination will play a crucial part in increasing public awareness about the HPV. The findings of the study indicated that HPV knowledge of nurses was found to be basis concerns and barriers to vaccination. In the current study, the education intervention effectively raised knowledge about HPV infection, HPV testing and HPV vaccine in nurses. This finding highlights the importance of increasing nurses' knowledge for the HPV infection, testing and prophylactic benefits of the HPV vaccine. However, although educational session was given to nurses, a few nurses vaccinated their daughters. Cost, safety and efficacy of vaccine was found basis concerns and barriers to vaccination. Future research and educational program should focus on vaccine safety, effectiveness and barriers to vaccination. Health providers and researchers should focus on overcome all social and cultural barriers.

\section{References}

Beydag KD (2011). Knowledge and applications of the midwives and nurses at an educational hospital on the early diagnosis of cervix cancer. Asian Pac J Cancer Prev, 12, 481-5.

Boyce T, Holmes A (2012). Addressing health inequalities in the delivery of the human papillomavirus vaccination programme: examining the role of the school nurse. Plos ONE, 7, 43416 .

Dinas K, Nasioutziki M, Arvanitidou O, et al (2009). Awareness of human papilomavirus infection, testing and vaccination in midwives and midwifery students in Greece. J Obstet Gyneacol, 29, 542-6.

Duval B, Gilca V, Boulianne N, et al (2009). Cervical cancer prevention by vaccination: nurses' knowledge, attitudes and intentions. J Adv Nurs, 65, 499-508.

Ferlay J, Shin HR, Bray F, et al (2010). Estimates of worldwide burden of cancer 2008: GLOBCAN 2008. Int J Cancer, 127, 2893-17.

Freidman AL, Shepeard H (2007). Exploring the knowledge, attitudes, beliefs and communication preferences of the general public regarding HPV: findings from CDC focus group research and implications for practice. Health Educ Behav, 34, 471-485.

Gottvall M, Tydén T, Höglund AT, Larsson M. (2010). Knowledge of human papillomavirus among high school students can be increased by an educational intervention. Int J STD AIDS, 21, 558-62.

Guvenc G, Akyuz A, Seven M (2012). Determination of the knowledge and attitudes of nursing students about human papilloma virus infection and its vaccines. Gulhane Med J, 54, 104-10.

Henninger J (2009) Human papilomavirus and papilomavirus vaccines: knowledge, attitudes and intentions of general practitioners and practice nurses in Christchurch. J Prim Health Care, 1, 278-85.

Hilton S, Hunt K, Bedford H, Petticrew M (2011). School nurses' experiences of delivering the UK HPV vaccination programme in its first year. BMC Infect Dis, 11, 226-34.

Holder NA, Katzenellenbogen R, Middleman AB (2013). Human papillomavirus vaccines: factors that affect vaccine knowledge and delivery. J Adolesc Health, 53, 423-5.

Hoque ME, Monokoane S, Van Hal G (2014). Knowledge of and attitude towards human papillomavirus infection and vaccines among nurses at a tertiary hospital in South Africa. J Obstet Gynaecol, 34, 182-6.

Klug SJ, Hukelmann M, Blettner M (2008). Knowledge about infection with human papilomavirus: a systematic review. Prev Med, 46, 87-98.

Kwan TT, Lo SS, Tam KF, Chan KK, Ngan HY (2012). Assessment of knowledge and stigmatizing attitudes related to human papilomavirus among Hong Kong Chinese healthcare providers. Int J Gynaecol Obstet, 116, 52-56.

Linnehan MJ, Andrews S, Groce NE (1996). College health providers' knowledge, attitudes and management practices of genital HPV infection. Nurse Pract, 21, 122-9.

Makwe CC, Anorlu RI (2011). Knowledge of and attitude toward human papilomavirus infection and vaccines among 
Emre Yanikkerem and Gokcen Koker female nurses at a tertiary hospital in Nigeria. Int $J$ Womens Health, 3, 313-7.

Marlow LA, Zimet GD, McCaffery KJ, Ostini R, Waller J (2013). Knowledge of human papillomavirus (HPV) and HPV vaccination: an international comparison. Vaccine, 31, 763-9.

McSherry LA, Dombrowski SU, Francis JJ, et al (2012). 'It's a can of worms': understanding primary care practitioners' behaviours in relation to HPV using the theoretical domains framework. Implement Sci, 3, 73 .

Naki MM, Celik H, Api O, et al (2010). Awareness, knowledge and attitudes related to HPV infection and vaccine among non-obstetrician gynecologist healthcare providers. J Turk Ger Gynecol Assoc, 11, 16-21.

National Cancer Institute. 2013. http://www.cancer.gov/ cancertopics/factsheet/Risk/HPV, Accessed: 30.06.2014

New Cervical Cancer Screening Recommendations from the U.S. Preventive Services Task Force and the American Cancer Society/American Society for Colposcopy and Cervical Pathology/American Society for Clinical Pathology https://www.acog.org/About_ACOG/Announcements/ New_Cervical_Cancer_Screening_Recommendations Accessed: 30.06.2014

Oldach BR, Katz ML (2012). Ohio Appalachia public health department personnel: human papillomavirus (HPV) vaccine availability, and acceptance and concerns among parents of male and female adolescents. J Community Health, 37, 1157-63.

Onsuz FM, Topuzoglu A, Bilgi Z, et al (2011). The evaluation of the knowledge levels and attitudes of medical students who have accomplished obstetric and gynecological diseases internship in a medical school about human papilloma virus vaccine. TAF Preventive Medicine Bulletin, 10, 557-564.

Ortashi O, Shallal M, Osman N, Raheel H (2012). Knowledge attitude and practice of school nurses in the United Arab Emirates about HPV infection and vaccine. Asian Pac J Cancer Prev, 13, 6481-84.

Ozan H, Demir BC, Atik Y, Gumus E, Ozerkan K (2011). Determination of knowledge level of patients regarding HPV and HPV vaccine in outpatient clinic of obstetrics and gynecology department. Uludag Med J, 37, 145-148.

Ozsaran Z, Demirci S, Aras AB (2011). A survey of evaluation medical students' level of knowledge about HPV Vaccine (Tip fakultesi ögrencileri arasinda HPV asisi bilgi duzeylerini degerlendiren anket calismasi). Turkish Journal of Gynecologic Oncology (Turk Jinekolojik Onkoloji Dergisi), 2, 40-44.

Ozyer S, Uzunlar O, Ozler S, et al (2013). Awareness of Turkish female adolescents and young women about HPV and their attitudes towards HPV vaccination. Asian Pac J Cancer Prev, 14, 4877-81.

Phianmongkhol Y, Suwan N, Srisomboon J, Kietpeerakool C (2011). Knowledge about human papilomavirus infection and cervical cancer prevention among nurses in Chiang Mai University Hospital, Thailand. Asian Pac J Cancer Prev, 12, 823-5.

Pinar G, Algier L, Colak M, Abbasoglu A (2007). Determination of nurses' knowledge about HPV vaccination and cervical cancer. Turk Jinekolojik Onkoloji Dergisi, 10, 94-8 (in Turkish).

Pinar G, Topuz S, An S, et al (2010). Evaluation of the level of HPV vaccination and cervix cancer knowledge of females admitted to baskent university ankara hospital, gynecology and obstetrics outpatient clinics Turk Jinekolojik Onkoloji Dergisi, 13, 11-18 (in Turkish).

Reiter PL, Stubbs B, Panozzo CA, Whitesell D, Brewer NT (2011). HPV and HPV vaccine education intervention: effects on parents, healthcare staff, and school staff. Cancer
Epidermal Biomarkers Prev, 20, 2354-61.

Riedesel JM, Rosenthal SI, Zimet G, et al (2005). Attitudes about human papillomavirus vaccine among family physicians. $J$ Pediatr Adolesc Gynecol, 18, 391-8.

Rosenthal SL, Weis TW, Zimet GD, et al (2011). Predictors of HPV vaccine uptake among women aged 19-26: importance of a physician's recommendation. Vaccine, 29, 890-5.

Tonguc E, Gungor T, Var T, et al (2013). Knowledge about HPV, relation between HPV and cervix cancer and acceptability of HPV vaccine in women in eastern region of Turkey. $J$ Gynecol Oncol, 24, 7-13.

Uzunlar O, Ozyer S, Baser E, et al (2013). A survey human papilomavirus awareness and acceptance of vaccination among nursing students in a tertiary hospital in Ankara, Turkey. Vaccine, 31, 2191-95.

Wamai RG, Ayissi CA, Oduwo GO et al (2013). Awareness, knowledge and beliefs about HPV, cervical cancer and HPV vaccines among nurse in Cameroon: an exploratory study. Int J Nurs Stud, 50, 1399-406.

Wong MC, Lee A, Ngali KL, Chor JC, Chan PK (2013). Knowledge, attitude, practice and barriers on vaccination against human papillomavirus infection: a cross-sectional study among primary care physicians in Hong Kong. Plos ONE, 8, 71827.

Wong YK, Do KY (2012). Are there socioeconomic disparities in women having discussions on human papillomavirus vaccine with health care providers? BMC Womens Health, 12, 33-39.

World Health Organization (2007). Human papillomavirus and HPV vaccines: technical information for policy-makers and health professionals initiative for vaccine research department of immunization, vaccines and biologicals. http://whqlibdoc.who.int/hq/2007/WHO_IVB_07.05_eng. pdf?ua=1, Accessed: 30.06 .2014

Yanikkerem E, Piyan G, Kavlak T, Karadeniz G (2010). Assessing the role of education on Turkish university students' knowledge about HPV and related diseases. Asian Pac J Cancer Prev, 11, 1703-11.

Yildirim M, Duzovali O, Kanik A, Kirik O (2009). Knowledge and attitudes of the pediatricians in Turkey regarding human papillomavirus (HPV) vaccine. J Pediatric Infection, 3, 62-68. 